\title{
The Changes of Electromyography in the Upper Trapezius and Supraspinatus of Women College Students According to the Method of Bag-carrying and Weight
}

\author{
Sung-Hyoun Cho, PT, PhD ${ }^{1)}$, Jung-Ho Lee, PT, PhD ${ }^{1}{ }^{*}$, Cheol-Yong Kim, PT, PhD ${ }^{2}$ \\ 1) Department of Physical Therapy, Daegu University Graduate school of Physical Therapy, Daegu \\ University: 15 Naeri-ri, Jinlyang, Gyeongsan-si, Kyeongsangbuk-do, Republic of Korea. \\ TEL: +82 10-2934-5433 \\ 2) Department of Physical Therapy, Ulsan College
}

\begin{abstract}
Purpose] The purpose of this study was to investigate differences in upper extremity muscle activities of women college students' due to method of bag-carrying and weight. [Subjects] Thirty healthy adult females participated in this study. The exclusion criteria were orthopedic or neurologic disease, or a dominant left side. [Methods] Electromyographic activities of the supraspinatus and upper trapezius were recorded bilaterally under two conditions: crossbody bag, ipsilateral bag. [Results] There were no significant differences in the supraspinatus and upper trapezius muscles according to the weight carried; however, there was significant difference in the right supraspinatus and both upper trapezius muscles according to the method of carrying. [Conclusion] An effective backpack safety program for female college students is necessary to educate them how to prevent possible musculoskeletal pain related to the weight carried and the method of carrying from the perspective of an ergonomical approach.

Key words: Carrying type, Bag weight, Electromyographic activity
\end{abstract}

(This article was submitted Mar. 19, 2013, and was accepted Apr. 26, 2013)

\section{INTRODUCTION}

People use different types of bag to carry the things they need in their daily lives. There are various types of bag such as backpacks and shoulder bags, and also various styles of carrying a bag ${ }^{1}$. When carrying a bag and walking, the body experiences physical stress due to the weight of the bag, and the body is either physiologically or mechanically influenced, which causes the dynamic balance and posture of the body to change ${ }^{2,3)}$.

Kim and Shin ${ }^{4}$ reported in their kinematic analysis on the change of posture due to the method of carrying a backpack that using only one strap to carry changes the angle of the shoulder and the spine the most and that using both straps increases the angle of the shoulder and the spine compared to when not carrying a bag. When weight is placed on only one side of the body, a person unconsciously raises the arms to the side or leans the body towards the opposite side to maintain balance and align the centerline with the center of the base of support ${ }^{3)}$. However, if the bag is overly heavy or if the method of carrying, the form of the bag, or the location of the bag is poor, the weight cannot be spread and an abnormal posture is adopted affecting the musculoskeletal system, causing pain and spinal disorders ${ }^{5)}$.

${ }^{*}$ To whom correspondence should be addressed.

E-mail: ljhcivapt@naver.com
Whittifield et al. ${ }^{6}$ reported that $77.1 \%$ of students complained about symptoms in their musculoskeletal system neck, waist, back, and shoulder. The authors claimed such symptoms are the result of various causes, and one of them is a heavy backpack. When students carry a bag asymmetrically, the transformation in the rotation of the trunk and asymmetry of the shoulders are significant when seen from both the coronal and the sagittal planes. It has also been reported that the distortion in posture increases as the weight of the bag increases. However, most previous research has used children or youths as their subjects ${ }^{7,8}$ ).

Recently, in the modern society, a growing number of fashion-conscious female university students consider a bag a part of their fashion. However, there is not enough study on the change in the shoulder posture due to carrying a bag when standing still. Therefore, this study analyzed the posture of shoulder muscles of female university students when carrying a crossbody bag on one shoulder or across the body using EMG analysis.

\section{SUBJECTS AND METHODS}

\section{Subjects}

The subjects of this study were 30 female students in their 20's attending U College. The selection criteria were students with no neurological, orthopedic, or visual disorders that would hinder balance, and the right hand as the 
1130 J. Phys. Ther. Sci. Vol. 25, No. 9, 2013

Table 1. Means and standard deviations $(\mathrm{M} \pm \mathrm{SD}$ ) of the supraspinatus and upper trapezius muscles (unit: $\mathrm{V}$ )

\begin{tabular}{lcccc}
\hline \multirow{2}{*}{ Muscle } & \multirow{3}{*}{ Carrying Type } & \multicolumn{3}{c}{ Weight of the bag } \\
\cline { 3 - 5 } & & $1 \mathrm{~kg}$ & $2 \mathrm{~kg}$ & $3 \mathrm{~kg}$ \\
\hline \multirow{2}{*}{ Left supraspinatus } & Ipsilateral & $12.01 \pm 9.91$ & $10.75 \pm 4.92$ & $15.03 \pm 10.41$ \\
& Opposite & $9.84 \pm 4.82$ & $13.80 \pm 8.41$ & $14.90 \pm 9.97$ \\
\multirow{2}{*}{ Right supraspinatus* } & Ipsilateral & $33.74 \pm 25.62$ & $35.82 \pm 23.91$ & $46.34 \pm 36.63$ \\
& Opposite & $22.05 \pm 16.81$ & $24.90 \pm 20.75$ & $28.16 \pm 23.88$ \\
Left upper trapezius* & Ipsilateral & $20.20 \pm 17.15$ & $19.04 \pm 14.65$ & $25.40 \pm 19.75$ \\
& Opposite & $27.85 \pm 16.41$ & $32.54 \pm 17.79$ & $34.20 \pm 22.63$ \\
\multirow{2}{*}{ Right upper trapezius* } & Ipsilateral & $42.47 \pm 34.91$ & $39.64 \pm 30.01$ & $51.96 \pm 40.01$ \\
& Opposite & $16.06 \pm 12.64$ & $16.95 \pm 11.92$ & $19.14 \pm 16.35$ \\
\hline
\end{tabular}

${ }^{*} \mathrm{p}<0.05$, Ipsilateral: bag carried on one side, Opposite: bag carried across the body on the opposite shoulder

dominant hand. The experiment was conducted from August 13th to August 24th of 2012. The subjects voluntarily agreed to participate in the experiment after receiving an oral explanation of the objective and the method of the experiment prior to the actual experiment.

\section{Methods}

This study employed a randomized crossover trial in which all subjects participated in the experiment without a specific order. The 30 participants were asked to carry the crossbody bag in two different styles with their right shoulder as the standard shoulder. The first method of carrying was to wear the crossbody bag on one side (right) and the second method was to wear it across the body on the opposite shoulder. According to $\mathrm{Ahn}^{1)}$ and Kim and Shin ${ }^{4)}$ wearing the crossbody bag on the shoulder places the upper part of the bag next to the crest of the ilium. The participants were asked to wear a comfortable top that exposed their shoulder, and then in a standing position, a pad was attached to their supraspinatus and upper trapezius to measure the muscle activity. In a quiet setting with no noise, the participants were told to begin the experiment that lasted exactly 30 seconds. The participants avoided pressuring the pad when wearing the bag. The weight of the bag was 1,2 , and $3 \mathrm{~kg}$, and the method of the experiment was the same for the two different methods of carrying the bag on the standard shoulder and on the opposite shoulder.

The experiment used a leather crossbody bag (width $35 \mathrm{~cm}$, height $23 \mathrm{~cm}, 500 \mathrm{~g}$ ) that female university students like to carry and all subjects used the same bag. In order to observe the change in the muscle activity by the weight of the bag, the experiment used dumbbells (Starsports Co., China). One $0.5 \mathrm{~kg}$ dumbbell and two $1 \mathrm{~kg}$ dumbbells were used.

We used a Biomonitor ME6000 (Mega Electronics Ltd., Finland) to measure the muscle activities of the upper trapezius and supraspinatus muscles while carrying the bag. The Mega Win version 2.2 (Mega Electronics Ltd., Finland) software was used to record and analyze the data. The electrodes on the two ends are active electrodes - silver disks with a diameter of $2 \mathrm{~cm}$, and the gray electrode in the center is a standard electrode with a diameter of $2 \mathrm{~cm}$. The distance between the standard electrode and the active elec- trodes was $2 \mathrm{~cm}$. The sampling rate of the EMG signal was set to $1,000 \mathrm{~Hz}$ and signals were full-wave rectified. The measured data were converted into root mean square (RMS) values and analyzed using the average values of three measurements. To reduce the skin resistance, hair and dead skin cells were removed from the skin where the electrodes were to be attached. The skin surface was wiped with alcohol on a cotton ball before attachment of the electrodes.

We used SPSS version 12.0 software (ICC Chicago, IL, USA) for the statistical analysis of the data. The mean and the standard deviation were calculated for each variable. To examine the significance of the change in the EMG due to the weight of the bag and carrying method, the repeated measures two-way ANOVA was used. Values of $p<0.05$ were considered statistically significant.

\section{RESULTS}

A total of 30 female university students participated. Their mean age was $22.70 \pm 2.40$ years, their mean height was $156.81 \pm 3.99 \mathrm{~cm}$, their mean weight was $55.15 \pm$ $3.67 \mathrm{~kg}$, and their mean body mass index was $22.46 \pm$ $1.57 \mathrm{~kg} / \mathrm{m}^{2}$. The mean and standard deviation of the four muscles according to the carrying method and the weight of the bag are shown in Table 1.

The change in the right supraspinatus between the carrying methods was 0.006 , which was statistically significant $(p<0.01)$, and the change in the left upper trapezius was 0.005 , which was also statistically significant $(p<0.01)$. The change in the right upper trapezius between the carrying methods was 0.004 , which was statistically significant $(p<0.01)$. The change in the left supraspinatus was not significant between the carrying methods, or weights of the bag, and the interaction between carrying method and weight of the bag. The changes in the right supraspinatus, left upper trapezius, and the right upper trapezius induced by the different weights were not significant $(p>0.05)$.

\section{DISCUSSION}

Motmans et al. ${ }^{9)}$ reported on the changes in EMG of the rectus abdominalis and erector spinae when carrying a bag at the back, at the front, at both the back and front, and switching sides while walking. They recommended 
avoiding carrying a bag across the body using only one shoulder when walking since the muscle activity of the two sides (left and right) would be asymmetric. Also, placing weight on one shoulder increases energy consumption ${ }^{10)}$ and causes a change in the EMG of both the legs and arms. If a subject continues placing weight on one side, the body unconsciously makes the trunk lose balance to maintain the balance from the external force creating an abnormal posture $^{11)}$. Since most adults usually use shoulder bags rather than backpacks, it is advisable to wear a crossbag across the body and on one side to reduce the lateral bending of the spine to the side opposite to the shoulder that is carrying the bag ${ }^{1)}$. According to a study of walking, oxygen consumption, metabolism, skin temperature, and volume of perspiration of elementary students increased with the weight of the bag; a heavy bag affects biomechanical aspects of the body and increases the energy consumption per hour ${ }^{12)}$. Such research has mainly covered the effect of walking and the weight of the bag on the general form of the body ${ }^{13,14)}$. Therefore, the present study was conducted to observe the muscle activities of both the supraspinatus and upper trapezius according to changes in bag weight. The subjects were female students attending U University. At each stage of the experiment, the weight of the bag changed, and for each bag weight, the participants were asked to change the carrying method of the crossbody bag to measure the shoulder muscle activity. The standards used for the bag weight was calculated by weighing the bags of 10 randomly selected female university students, which ranged from $1.2 \mathrm{~kg}$ to $2.8 \mathrm{~kg}$. Thus, the experiment used bag weights of 1,2 , and $3 \mathrm{~kg}$. The participants only used their right shoulder to carry the bag: carried on the side and across the body.

The results show that the change in the muscle activity of the upper trapezius was not statistically significant between the carrying methods, and the bag weights. The changes in the right supraspinatus, and left and right upper trapezius were significant between the carrying methods. However, the changes were not significant among the bag weights or between the carrying methods. This study failed to consider variables such as differences in subjects' height and weight when carrying a bag of the same weight. A systematic future study will be needed of subjects with the same characteristics (age, height, weight, and activities of shoulder muscles) carrying bags of different weights.

Negrini and Negrini ${ }^{15)}$ studied the change in the trunk, shoulder, and spine when students walked 7 minutes carrying a bag on their shoulder and carrying a bag on their back, and reported that lateral bending was observed on the side opposite to the side on which the weight was placed, and shoulder elevation was also observed. This study was unable to directly compare both shoulders since the participants were asked to carry the bag using only one shoulder. In addition, the study of Jeong ${ }^{8)}$ proposed that bag weight is not directly correlated with back pain, but has a significant correlation with shoulder pain. The present study showed that the changes in the muscle activities of the right supraspinatus, and left and right upper trapezius were statistically significant. Therefore, one needs to be mindful of pain or posture transformation that follows asymmetric muscle activity due to the carrying method.

Limitations of this study were that the subjects were normal not patients, we did not measure the muscle activities when the subjects were not carrying the bag, which may have been a cause of the significant differences seen in the results, the length of the bag strap was the same for all subjects, and we did not consider the height of the subjects. Future research will need to change the load by adjusting the length of strap according to the height and weight of individuals and to observe the changes in muscle activities according to the weight of a bag, the carrying method, and the length of its strap.

\section{REFERENCES}

1) Ahn JS: The effects of asymmmetric load of shoulder bag on trunk and pelvis movement patterns of normal adult during gait. Graduate School of Health and Environment, Yonsei University, 2006.

2) $\mathrm{Oh} \mathrm{JH}$, Choi $\mathrm{SN}$ : Effects of the length of schoolbag string on gait posture. J Sport Leis Stud, 2007, 30: 619-629.

3) Matsuo $T$, Hashimoto $M$, Koyanagi M, et al.: Asymmetric load-carrying in young and elderly women: relationship with lower coordination. Gait Posture, 2008, 28: 517-520. [Medline] [CrossRef]

4) Kim CK, Shin DM: Kinematic analysis of book bag weight on gait cycle and posture of youth. J Sport Leis Stud, 1995, 3: 175-185.

5) Whittfield JK, Legg SJ, Hedderley DI: The weight and use of schoolbags in New Zealand secondary schools. Ergonomics, 2001, 44: 819-824. [Medline]

6) Whittfield J, Legg SJ, Hedderley DI: Schoolbag weight and musculoskeletal symptoms in New Zealand secondary schools. Appl Ergon, 2005, 36: 193-198. [Medline] [CrossRef]

7) Kim JS, Kim K, Jun DH: The effect of changes in young women's static balance after performing walking task with different carrying bag positions. Korean Soc Phys Med, 2011, 6: 51-58.

8) Jung MY: Correlation between perceived backpack weight and musculoskeletal pain for elementary school children. J Ergonomics Soc Korea, 2006, 25: 35-40. [CrossRef]

9) Motmans RR, Tomlow S, Vissers D: Trunk muscle activity in different modes of carrying schoolbag. Ergonomics, 2006, 49: 127-138. [Medline] [CrossRef]

10) Legg SJ, Mahantry A: Comparison of five modes of carrying a load close to the trunk. Ergonomics, 1985, 28: 1653-1660. [Medline] [CrossRef]

11) Neumann DA, Cook TM: Effect of load and carrying position on the electromyographic activity of the gluteus medius muscle during gait. Phys Ther, 1985, 65: 305-311. [Medline]

12) Jo SC: Effects of backpack weight on elementary school boy's walking. Korean Soc Sports Med, 2001, 19: 303-310.

13) Filaire M, Vacheron JJ, Vanneuville G: Influence of the mode of load carriage on the static posture of the pelvic girdle and the thoracic and lumbar spine in vivo. Surg Radiol Anat, 2001, 23: 27-31. [Medline] [CrossRef]

14) Smith B, Ashton KM, Bohl D: Influence of carrying a backpack on pelvic tilt, rotation, and obliquity in female college students. Gait Posture, 2006, 23: 263-267. [Medline] [CrossRef]

15) Negrini S, Negrini A: Postural effects of symmetrical and asymmetrical loads on the spines of schoolchildren. Scoliosis, 2007, 2: 8-14. [Medline] [CrossRef] 